\title{
The auditory roles of the gas bladder and suprabranchial chamber in walking catfish (Clarias batrachus)
}

\author{
Yi Ta Shao ${ }^{1,2}$, I-Shiung Chen ${ }^{2}$ and Hong Young Yan ${ }^{1,3^{*}}$
}

\begin{abstract}
Background: The enhanced auditory abilities of certain fish are dependent on specialized hearing structures. Several gas-holding structures, including the suprabranchial chamber, otic gas bladder, and Weberian apparatus-linked gas bladder, have been demonstrated to improve the hearing ability of fish. The walking catfish (Clarias batrachus), a benthic species, is unique in that it has both a suprabranchial chamber (SC) and a Weberian apparatus-linked, encapsulated gas bladder (WGB). This study aimed to investigate the respective roles of these two structures in contributing to the overall hearing ability of walking catfish.
\end{abstract}

Results: The auditory evoked potentials method was used to measure hearing thresholds in intact fish and fish with a deflated WGB and/or SC. Gas removal from the WGB increased auditory thresholds at all frequencies tested $(0.4$ to $5.0 \mathrm{kHz}$ ), whereas injection of water into the SC shifted the threshold only at frequencies below $3.0 \mathrm{kHz}$. However, such a correlation was not observed for the SC at 4.0 and $5.0 \mathrm{kHz}$.

Conclusions: The findings indicated that both the encapsulated WGB and the SC had an accessory auditory role. However, WGB enhanced hearing abilities in the whole frequency range, whereas SC did not.

Keywords: Hearing ability; AEP; Catfish; Weberian apparatus; Suprabranchial chamber

\section{Background}

Physical restrictions prevent most fish from detecting all but low-frequency sounds (see review in Hawkins and Myrberg 1983). However, several non-related groups of teleost fishes have evolved mechanisms that enhance hearing ability; such mechanisms involve the transmission of the pressure component of passing sound waves to the inner ear via gas-holding structures (see reviews in Yan 2004; Ladich and Popper 2004). The Weberian apparatus, an ossicular chain that involve a set of minute bones originating from the first few vertebrae, which connect inner ear to the swim bladder, exists in all Otophysi, i.e., Characiformes, Cypriniformes, Gymnotiformes, and Siluriformes (Nelson 2006). The Weberian apparatuslinked gas bladder (WGB) is the best known of the

\footnotetext{
* Correspondence: hyyan@gate.sinica.edu.tw

${ }^{1}$ Marine Research Station, Institute of Cellular and Organismic Biology,

Academia Sinica, 23-10, Dawen Road, Jiaoshi 26242, Taiwan

${ }^{3}$ Hanse-Wissenschaftskolleg Institute for Advanced Study, Lehmkuhlenbusch 4,

Delmenhorst 27753, Germany

Full list of author information is available at the end of the article
}

structures that aid hearing (see reviews in Fay and Popper 1975; Yan and Curtsinger 2000; Yan et al. 2000). Its auditory aid function has been proven in Brown bullhead (Ameiurus nebulosus), common roach (Rutilus rutilus) as well as gold fish (Carassius auratus) in early studies (Kleerekoper and Roggenkamp 1959; Laming and Morrow 1981; Fay and Popper 1974). After WGBwas mutilated or deflated, hearing thresholds of those species significantly increased compared to that of the intact fish. Furthermore, hearing abilities of Otophysi are highly dependent on the number of Weberian ossicles and the size of the gasbladder, what has been shown inseveral catfish species (Lechner and Ladich 2008).

Other gas-holding structures in the fish body, such as the suprabranchial chamber (SC) in Anabantoidei and the otic gas bladder in Mormyridae, connect directly to the inner ear and are thus also capable of enhancing hearing ability (Yan and Curtsinger 2000; Yan 2004). The SC is a respiratory organ found in gouramis (Anabantoidei) of the families Anabantidae, Helostomatidae, and Osphronemidae. Catfishes of the family Clariidae 
have a similar structure (SC) as well. The SC enhances the hearing ability in gouramis, what has been shown in several species such as paradise fish (Macropodus opercularis, Osphronemidae) (see reviews in Yan 1998), blue gouramis (Trichogaster trichopterus; Osphronemidae), dwarf gouramis (Colisa lalia; Osphronemidae), and kissing gouramis (Helostoma temminckii; Helostomatidae) (Yan 1998).

Certain benthic catfishes, such as Loricariidae and Callichthyidae, have small, paired, and encapsulated WGB (see reviews in Chardon et al. 2003). Lechner and Ladich (2008) suggested that although such bladders reduce buoyancy compared to the catfishes with single and large WGB, their auditory function ensured their retention through evolution. The auditory role of such bladders have been previously demonstrated in oto catfish (Otocinclus affinis; Loricariidae); hearing thresholds at 0.5 to $10.0 \mathrm{kHz}$ are significantly increased by deflation of the WGB in this species (Botta 2009). Walking catfish (Clarias batrachus; Clariidae), on the other hand, possess both a SC and a single encapsulated WGB (Bridge and Haddon 1893; Alexander 1964; Chardon et al. 2003), and thus, auditory compensation in this species may differ to that in the oto catfish. The respective contributions of the WGB and SCto sound detection have not previously been compared in teleosts possessing both of these organs.

The main objectives of the present study were to (1) establish whether the encapsulated WGB and SC of walking catfish play a role in hearing enhancement, (2) determine whether the accessory auditory functions of those two structures are independent, and (3) investigate the frequency ranges in which they improve hearing ability. The auditory evoked potentials (AEP) method was used to determine the auditory function of the WGB and SC in walking catfish via shifts in hearing thresholds before and after gas removal.

\section{Methods}

\section{Animal preparation and protocols}

Walking catfish (C. batrachus) used in this study were obtained from a local aquarium shop. The standard lengths and weights of the catfish used were 50 to $65 \mathrm{~mm}$ and 11.0 to $16.5 \mathrm{~g}$ for experiment 1 and 60 to $110 \mathrm{~mm}$ and 14.0 to $25.5 \mathrm{~g}$ for experiment 2, respectively. Fish were housed in two $144 \mathrm{~L}$ aquaria with charcoal-filtered running water. The temperature was maintained at $25^{\circ} \mathrm{C}$ to $28^{\circ} \mathrm{C}$, and fish were maintained under a natural photoperiod. Two sets of experiments were conducted. In experiment 1 , the AEP method was used to measure the hearing thresholds of three experimental groups of catfish (SC deflated $(n=5)$, WGB deflated $(n=5)$, and both SC and WGB deflated $(n=4))$ and a control group of intact catfish $(n=5)$. In experiment 2 , hearing thresholds were measured before and after gas removal from either the WGB $(n=4)$ or the SC $(n=5)$. After surgery, operated catfish were placed into an aquarium to enable their SC or WGB to be replenished with gas; after which, audiograms were subsequently measured again. The color patterns of each fish were recorded; hence, they could be identified easily by their unique patterns. The recovery period of the SC-deflated group was 3 days, which was followed by the previous report on gouramis SC-deflated experiment (Yan 1998). For the WGBdeflated group, digital X-rays (Intermedical Basic 4003) were used to inspect the WGBevery 3 days until it was completely replenished with gas; full recovery took 21 days (Figure 1). Furthermore, in experiment 2, initial and recovery fish in WGB-deflated group were shamoperated before AEP measurement.

\section{Removal of gas from the WGB and SC}

Before undergoing surgery, catfish were anaesthetized with a $0.025 \%$ buffered MS-222 (ethyl 3-aminobenzoate methanesulfonic acid salt, Sigma, St. Louis, MO, USA) solution for $2 \mathrm{~min}$.

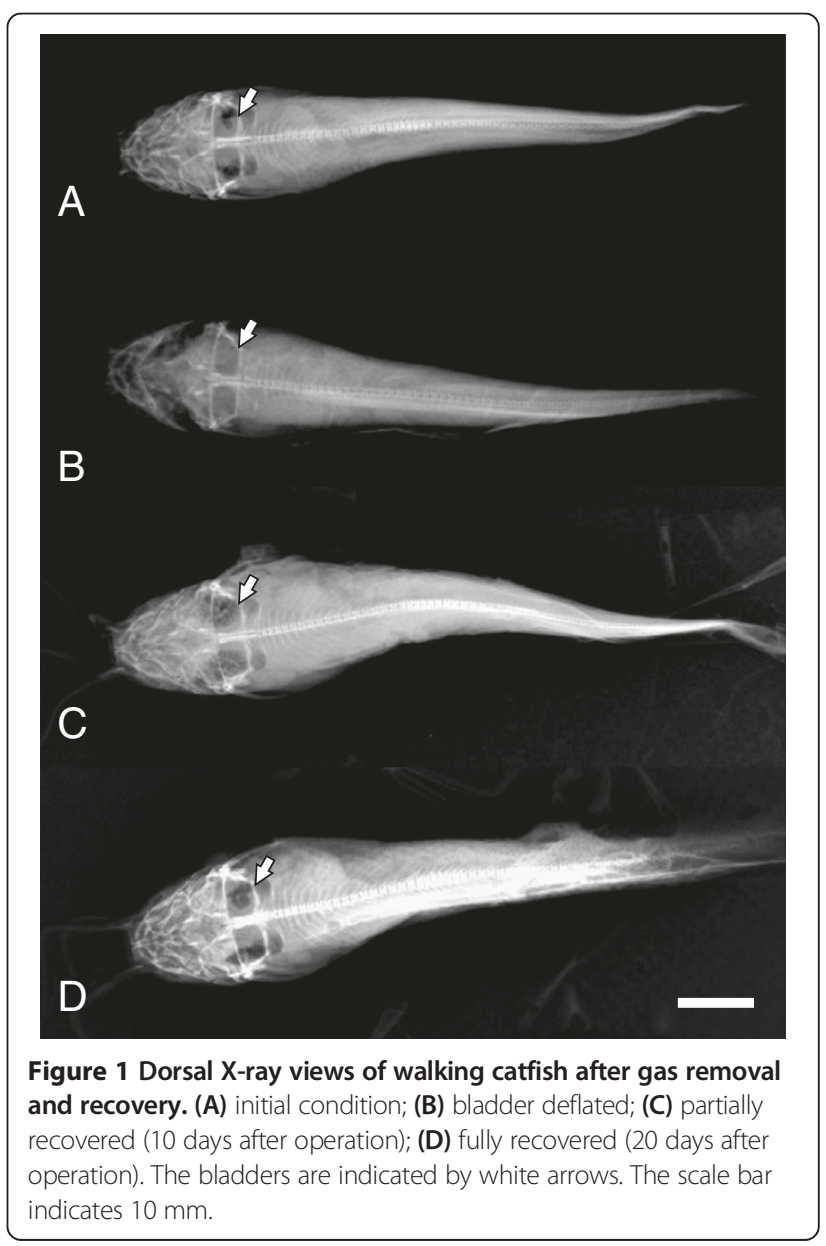


Unlike the paired, encapsulated bladders described in other benthic catfishes (Bridge and Haddon 1893; Alexander 1964; Lechner and Ladich 2008; Botta 2009), a single bladder with a shortened mid-ridge is present in walking catfish (Alexander 1964). In experiment 1, gas inside the WGB was drawn out slowly with an insulin syringe (Ultra-fine II U-100, Becton, Dickinson and Company, Franklin Lake, NJ, USA) from both sides of the lateral cutaneous area between the posterior of the operculum and the base of the pectoral fin, along the dorsal edge of the clavicle; this region was selected as it allowed the syringe to access the bladder while avoiding the thickened and calcified bony capsules (Alexander 1964). However, this operation was found to cause high mortality. In order to reduce stress and to improve survival, the gas removal protocol was modified in experiment 2 to use a 30-G insulin syringe needle (\#305107, BD PrecisionGlide Needle, Becton, Dickinson and Company, Franklin Lake, NJ, USA) to pierce the bladder from one side of the lateral cutaneous area. The gas inside the WGB was then driven out by injecting Holmes and Stott freshwater teleost physiological saline (see review in Wolf 1963) from the other side of the bladder with a second U-100 insulin syringe, until gas bubbles stopped emerging from the first needle. The insulin syringe was initially loaded with $300 \mu \mathrm{l}$ of saline $(0.303 \mathrm{~g}$; density $=1.010 \mathrm{~g} / \mathrm{ml})$, and the remaining saline was weighed after injection. The volume of saline injected into the WGB was calculated by subtracting the final weight from the initial weight (volume = weight/1.010), and this was considered to be equal to the volume of gas in the WGB. Digital X-rays were used to locate the bladder prior to surgery and to confirm gas removal afterward. The entire treatment was performed underwater to prevent air from re-entering the bladder via the incision. Fish were unable to maintain neutral buoyancy after the operation. X-ray examination confirmed that gas was not replenished during the experiment.

Gas was removed from the $\mathrm{SC}$ as described in the study of Yan (1998). Gas in the SC was driven out by water injected through soft polyethylene tubing (Clay Adams, inner diameter $1.19 \mathrm{~mm}$ ) connected to a 20- to 200- $\mu$ l pipette (Rainin, Mettler Toledo, Columbus, $\mathrm{OH}$, USA). The fish were held upside down in water during the operation, and the tube was inserted deeply through both sides of the gill to reach the SC. Water was then injected slowly into the chamber until gas bubbles stopped emerging from the gill opening. The pipette was initially loaded with $200 \mu \mathrm{l}$ of water $(0.200 \mathrm{~g}$; density $=1 \mathrm{~g} / \mathrm{ml})$, and the remaining water was weighed after injection. The volume of water injected into the $\mathrm{SC}$ was calculated by subtracting the final weight from the initial weight, and this was considered to be equal to the volume of gas in the SC. The fish were kept underwater during surgery and
AEP measurements to prevent the SC from refilling with gas.

\section{Hearing threshold determination}

The AEP recording protocol used in this study followed that of Kenyon et al. (1998). The fish were immobilized by intramuscular injection of gallamine triethiodide (Flaxedil; Sigma, St. Louis, MO, USA), a neuromuscular blocking agent, into the dorsal muscle $(0.2$ to $0.3 \mu \mathrm{g}$ per gram of body weight). Treated fish were wrapped in wet Kimwipes (Kimberley-Clark Irving, TX, USA) to prevent scraping of the skin and were held in place with nylon mesh. The mesh was fixed to a stainless steel rod attached to a micromanipulator. Fish were suspended in a plastic tub $(24 \times$ $24 \times 10 \mathrm{~cm}$ ) filled with fresh water, with the top of the head kept at about $2 \mathrm{~mm}$ above the water surface. In order to keep the fish alive during the experiment, a small tube was used to irrigate the gills with oxygenated water during the recordings.

A recording electrode (a Teflon-coated silver wire, $0.25 \mathrm{~mm}$ in diameter with a 1-mm exposed tip) was placed on the midline of the skull between the eyes. A reference electrode of a similar specification was placed $0.5 \mathrm{~cm}$ ahead of the recording electrode. EEG paste (Ten $20^{\circ}$ conductive EEG paste, D.O. Weaver and Co., Aurora, CO, USA) was used to cover the area of skin attached to the electrodes, in order to enhance the conduction of evoked potentials from the brain to the electrodes. Eyeball rotation and barbel movement under tactile stimulation were used as indicators that the fish were still alive during the recordings.

The experimental setup was placed on a vibration-free air table (Vibraplane, Kinetic Systems, Boston, MA, USA) located inside a soundproof room $(1.9 \times 1.6 \times$ $2.6 \mathrm{~m}$ ) to minimize disturbances from noise and vibration. Signals recorded from the electrodes were amplified and converted to digital signals by a preamplifier (HS4, Tucker-Davis Technologies, Alachua, FL, USA) and transmitted from the soundproof room via an optical fiber. Sound stimuli at frequencies up to $2.0 \mathrm{kHz}$ were produced using a $30-\mathrm{cm}$ diameter woofer $(4$ to $8 \Omega$, Panasonic), while sounds at frequencies above $2.0 \mathrm{kHz}$ were generated using a 12.5 -cm diameter tweeter (7.25 $\Omega$, Pyle). The speaker was suspended $1.25 \mathrm{~m}$ above the test subjects.

Sound stimuli and AEP waves were generated and recorded by a Tucker-Davis Technologies (TDT) (Gainesville, FL, USA) modular rack mount system, which was controlled by a TDT AP2 board with TDT BioSig software.

Sound stimuli at each frequency and pressure level consisted of 2,000 repeats of a 20-ms tone burst. Each stimulus was played twice for each test fish. In order to calibrate the sound pressure level of the stimulations in water, a hydrophone (Celesco LC-10) was placed near 
the head of the fish. The signal from the hydrophone was amplified 100 times using a differential preamplifier (Grass P-15, bandpass, 10 to $10,000 \mathrm{~Hz}$ ) and calibrated in absolute units $(\mathrm{dB}$ re $1 \mu \mathrm{Pa})$.

Each experiment started at the highest sound pressure level (SPL) to induce suprathreshold responses; the SPL was then reduced in $5 \mathrm{~dB}$ steps until traceable and repeatable waveforms were no longer detectable (Kenyon et al. 1998; Yan and Curtsinger 2000; Akamatsu et al. 2003). Since the main purpose of the present study was aimed at understanding the respective auditory roles of $\mathrm{SC}$ and WGB, therefore, frequencies lower than $0.4 \mathrm{kHz}$ were not investigated in the present study because many studies have indicated that stimuli below $0.4 \mathrm{kHz}$ could trigger evoked potentials of lateral line which could compound the intended studies of auditory functions (Harris and van Bergeijk 1962; Münz 1989; Kroese and Schellart 1992; Kenyon et al. 1998). In experiment 1, hearing threshold levels were determined at the following frequencies: $0.4,0.6,0.8,1.0,1.5,2.0,2.5,3.0,4.0$, and $5.0 \mathrm{kHz}$. In experiment 2, tested frequencies have been simplified to reduce fish stresses and increase survival rate. They were determined at the following frequencies: $0.6,1.0,2.0,3.0$, and $5.0 \mathrm{kHz}$. SPLs were tested from the maximal output (about 150 to $142 \mathrm{~dB}$ for 0.4 to $1.0 \mathrm{kHz} ; 145$ to $139 \mathrm{~dB}$ for 1.5 to $2.5 \mathrm{kHz} ; 135$ to $131 \mathrm{~dB}$ for 3.0 to $5.0 \mathrm{kHz}$, in water) to the lowest threshold levels. At each frequency, the threshold shift (delta threshold) caused by the removal of gas from the WGB and/or SC was taken as their auditory aid ability.

The experiments were carried out following permission (RFiZOOYH2006120) issued from the Institutional Animal Care and Use Committee (IACUC) of Academia Sinica.

\section{Statistical analysis}

Comparisons between two independent samples were performed by analyzing the data with two-tailed Student's ttest. Comparisons between multiple groups were performed using one-way ANOVA and Tukey's post hoc test $(p<0.05)$. Two-way ANOVA was applied to analyze the factors of stimuli frequencies and treatments. For experiment 2 , hearing thresholds of each individual before and after gas removal were compared and threshold shifts were calculated. Relationships between gas volume in the gas bladder or suprabranchial chamber and hearing ability were determined by Pearson's correlation coefficients and linear regressions. All statistical tests were performed with SPSS v.14 (SPSS Inc., Chicago, IL, USA).

\section{Results}

\section{Experiment 1}

Figure 2 shows a series of AEP waveforms of walking catfish in response to 0.6 to $5.0 \mathrm{kHz}$ tone bursts, at sound pressure levels of $120 \mathrm{~dB}$. A typical AEP waveform consisted of a series of peaks. In intact catfish (Figure 2, black lines), these peaks were readily apparent. However, the peaks in catfish with a deflated SC (Figure 2, red lines), WGB (Figure 2, blue lines), or both (Figure 2, green lines) were less prominent.

AEPthresholds for tone bursts between 0.4 and $5.0 \mathrm{kHz}$ are shown for intact and SC- and/or WGBdeflated catfish in Figure 3. Two-way ANOVA showed that the threshold curves were highly frequencydependent $(p<0.01)$, and treatments did have significant effect on the thresholds $(p<0.05)$. Furthermore, the clear interaction $(p<0.05)$ of those two factors indicated that the treatment effects on hearing thresholds were frequency-dependent as well.

The lowest hearing threshold of intact catfish was found to be $0.6 \mathrm{kHz}$, with $83.8 \pm 2.2 \mathrm{~dB}$ (mean $\pm \mathrm{SE}$ ). For intact catfish, no significant differences $(p>0.05$ for all comparisons) were detected at frequencies between 0.6 and $2.5 \mathrm{kHz}$; the mean threshold over these frequencies was $87.8 \pm 3.1 \mathrm{~dB}$. Thresholds increased gradually above $3.0 \mathrm{kHz}$ (Figure 3).

At frequencies below $3.0 \mathrm{kHz}$, the hearing thresholds of s-deflated fish were significantly higher than those of the intact fish $(p<0.05$ at $0.4 \mathrm{kHz}$ and $3.0 \mathrm{kHz} ; p<0.001$ at 0.6 to $2.5 \mathrm{kHz}$ ), but such a difference was not observed at frequencies 4.0 and $5.0 \mathrm{kHz} \quad(p>0.05)$ (Figure 3).

At frequencies between 0.4 and $1.5 \mathrm{kHz}$, the hearing thresholds of WGB-deflated fish were no different to those of the SC-deflated fish; however, above $2.0 \mathrm{kHz}$, the thresholds of WGB-deflated fish were higher than those of the SC-deflated fish $(p<0.05$ at 2.0 and $2.5 \mathrm{kHz}$; $p<0.005$ at other frequencies) (Figure 3).

The hearing thresholds of SC- and WGB-deflated fish were significantly higher than those of the intact catfish at all tested frequencies $(p<0.05$ at $0.4 \mathrm{kHz} ; p<0.001$ at other frequencies) (Figure 3). Moreover, the thresholds of SC- and WGB-deflated fish were higher than those of the SC-deflated fish at frequencies above $0.6 \mathrm{kHz}(p<$ 0.05 at 0.6 and $0.8 \mathrm{kHz} ; p<0.005$ at frequencies above $1.0 \mathrm{kHz}$ ) and higher than those of the WGB-deflated fish at frequencies below $2.5 \mathrm{kHz}(p<0.05$ at all frequencies) (Figure 3).

\section{Experiment 2}

The baseline hearing thresholds observed in this experiment were not different to those recorded in intact fish in experiment 1 . Catfish recovered from WGB deflation after 21 days and exhibited a significant increase in weight after recovery (initial, $19.1 \pm 3.4 \mathrm{~g}$; post-recovery, $27.2 \pm 4.5$ g; $p<0.05$ ); on the other hand, no change in weight was observed after recovery from SC deflation. No significant differences in hearing thresholds were 


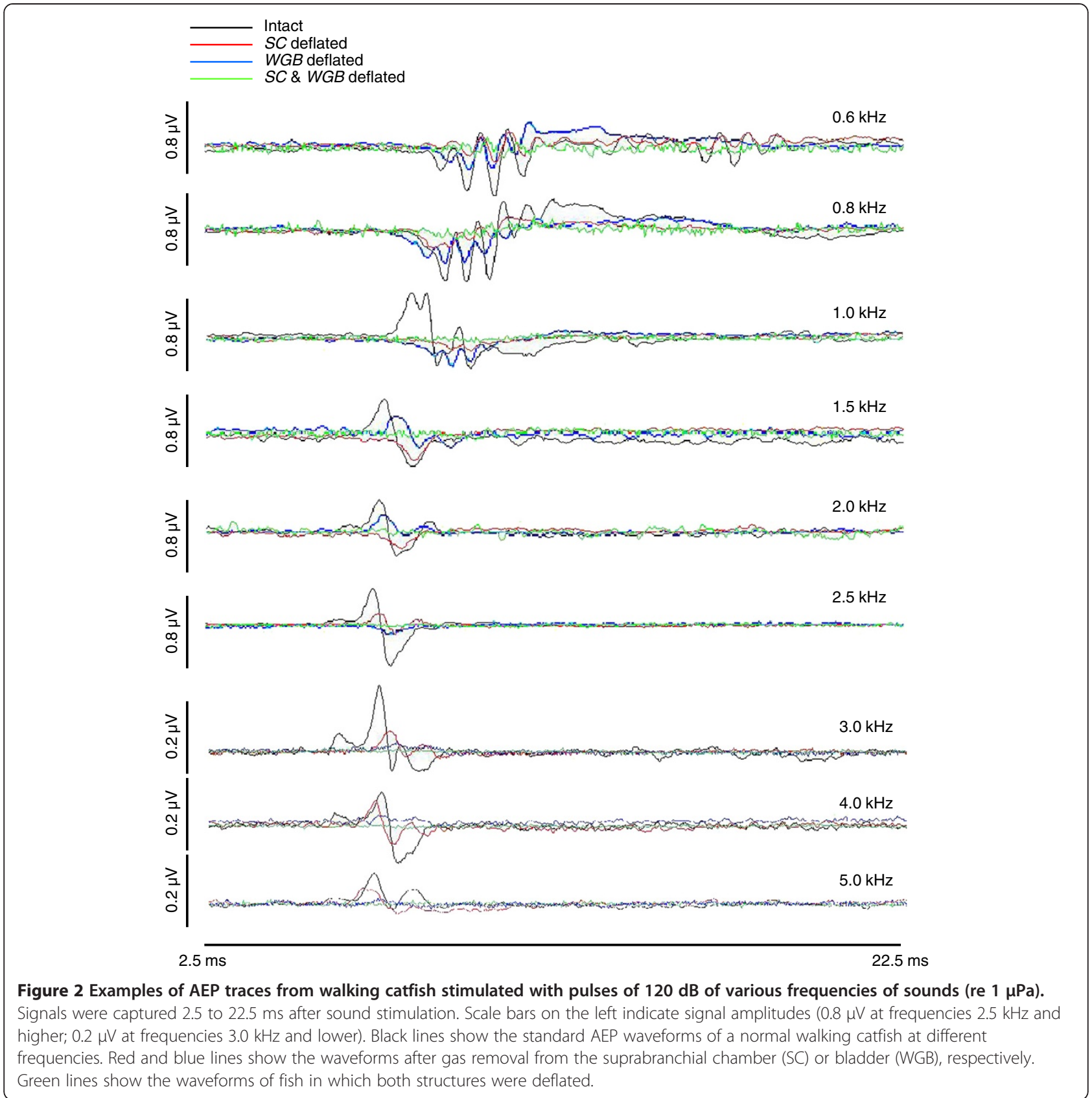

observed between baseline and recovery for both the SC-deflated (Figure 4A; $p>0.05$ ) and WGB-deflated groups (Figure $4 \mathrm{~B} ; p>0.05$ ), indicating that hearing ability was restored after recovery.

Flushing out all gas bubbles from the SC significantly increased thresholds at $0.6,1.0$, and $2.0 \mathrm{kHz}(p<0.05$ at 0.6 and $2.0 \mathrm{kHz} ; p<0.005$ at $1.0 \mathrm{kHz}$ ) but not at higher frequencies $(p>0.05)$ (Figure 5A). At 0.6, 1.0, and $2.0 \mathrm{kHz}$, the mean threshold shift was $21.8 \pm 3.4 \mathrm{~dB}$, and no significant difference was observed among these frequencies (Figure 5A). On the other hand, an increase in auditory threshold was observed at all frequencies after gas removal from the WGB $(p<0.005)$ (Figure 5B). The maximum shift in the hearing threshold after WGB deflation $(32.7 \pm 1.9 \mathrm{~dB})$ was observed at $2.0 \mathrm{kHz}$, and this was significantly higher than at other frequencies (19.1 to $25.6 \mathrm{~dB})(p<0.005$ as compared to $1.0 \mathrm{kHz} ; p<0.05$ as compared to other frequencies) (Figure 5B).

The mean SC and WGB total volumes for walking catfish were $359 \mu \mathrm{l}$ (ranging from 290 to $420 \mu \mathrm{l}$ ) and $243 \mu \mathrm{l}$ (ranging from 150 to $300 \mu \mathrm{l}$ ), respectively. No significant correlation was observed between $S C$ volume and its ability to enhance hearing ( $p>0.2$ at all frequencies) (Figure 6). However, significant positive correlations 


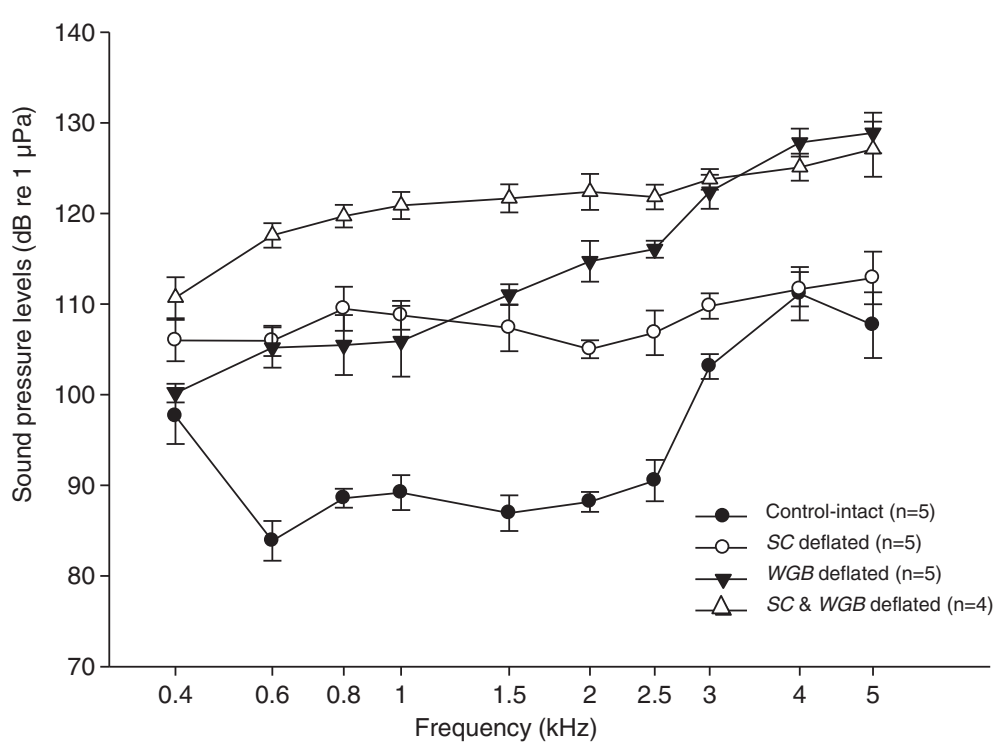

Figure 3 Audiograms of walking catfish at the indicated frequencies. Audiograms are shown for intact catfish (control) and fish with a deflated suprabranchial chamber (SC) and/or bladder (WGB). Data are shown as means \pm SE (statistical analysis is described in the 'Results' section).

between WGB volume and threshold shifts after gas removal were observed at 3.0 and $5.0 \mathrm{kHz}(p<0.05)$ (Figure 7).

\section{Discussion}

\section{Hearing thresholds of walking catfish}

The AEP waveforms shown in Figure 2 were clearly modulated by frequency; with the reduced amplitude and shorter latency time of AEP waveforms at higher frequencies, these are the two hallmarks of typical AEP waveforms (Kenyon et al. 1998). Moreover, we observed that the AEP thresholds increased with frequency (i.e., hearing abilities decreased), with a clear shift occurring at $3.0 \mathrm{kHz}$ (Figure 3). The most sensitive frequency range of hearing in walking catfish was between 0.6 and $2.5 \mathrm{kHz}$, which is largely consistent with the sensitive frequency range observed in other catfishes (Figure 8) (data re-plotted from Tavolga 1982; Ladich 1999; Lechner and Ladich 2008; Botta 2009; Wysocki et al. 2009; Lechner et al. 2010; Lechner et al. 2011; Zebedin and Ladich 2013). However, certain differences were observed between 0.8 and $2.0 \mathrm{kHz}$ stimulation. While the mean auditory thresholds in catfish with a free bladder were between 77 and $81 \mathrm{~dB}$, those with an encapsulated bladder were between 90 and 102 dB (data from Tavolga 1982; Ladich 1999; Lechner and Ladich 2008; Botta 2009; Wysocki et al. 2009; Lechner et al. 2010; Lechner et al. 2011; Zebedin and Ladich 2013). Despite the encapsulation of gas bladders that may help keep surrounding tissue separate from the moving part of the bladder wall (Alexander 1966), the bony encapsulation results in a decrease in sensitivity probably because the walls of this air-filled chambers are not free to vibrate (Lechner and Ladich 2008; Kratochvil and Ladich 2000). The present study revealed that the sensitivity of walking catfish was similar to the sensitivity of catfishes having tiny and small encapsulated bladders, which was far poorer than what is found in free bladder catfishes (Figure 8).

\section{Effects of gas in the SC and WGB on hearing}

The removal of gas from the WGB or SC significantly reduced the amplitudes of the AEP waveforms in walking catfish. Moreover, these procedures resulted in a threshold increase at certain frequencies. When the fish were allowed to recover so that their deflated WGB or SC refilled with gas through normal physiological mechanisms, their hearing sensitivity was restored. This gas removal and replenishment experiment corroborated the conclusions of earlier studies (see review in Yan 2004); namely, that the gas inside these two structures enhances the hearing abilities of various fish species.

In experiment 2, gas removal from the WGB increased the hearing threshold at all frequencies tested (0.6 to $5.0 \mathrm{kHz}$ ), with a mean increase of $22.8 \pm 4.1 \mathrm{~dB}$ (mean \pm $\mathrm{SE})$. These findings are largely in agreement with those in WGB-deflated oto catfish (0.5 to $1.0 \mathrm{kHz} ; 20.3 \pm$ $2.1 \mathrm{~dB}$ ) (Botta 2009). While gas removal in oto catfish primarily increased the threshold between 0.8 and $1.5 \mathrm{kHz}(22.6 \pm 0.9 \mathrm{~dB})$, the major threshold shift in walking catfish occurred at higher frequencies (2.0 to $2.5 \mathrm{kHz})$ and to a greater extent $(32.8 \pm 1.9 \mathrm{~dB})$. In addition to catfishes, certain Cypriniformes also possess an encapsulated bladder. For example, the cobitid, 

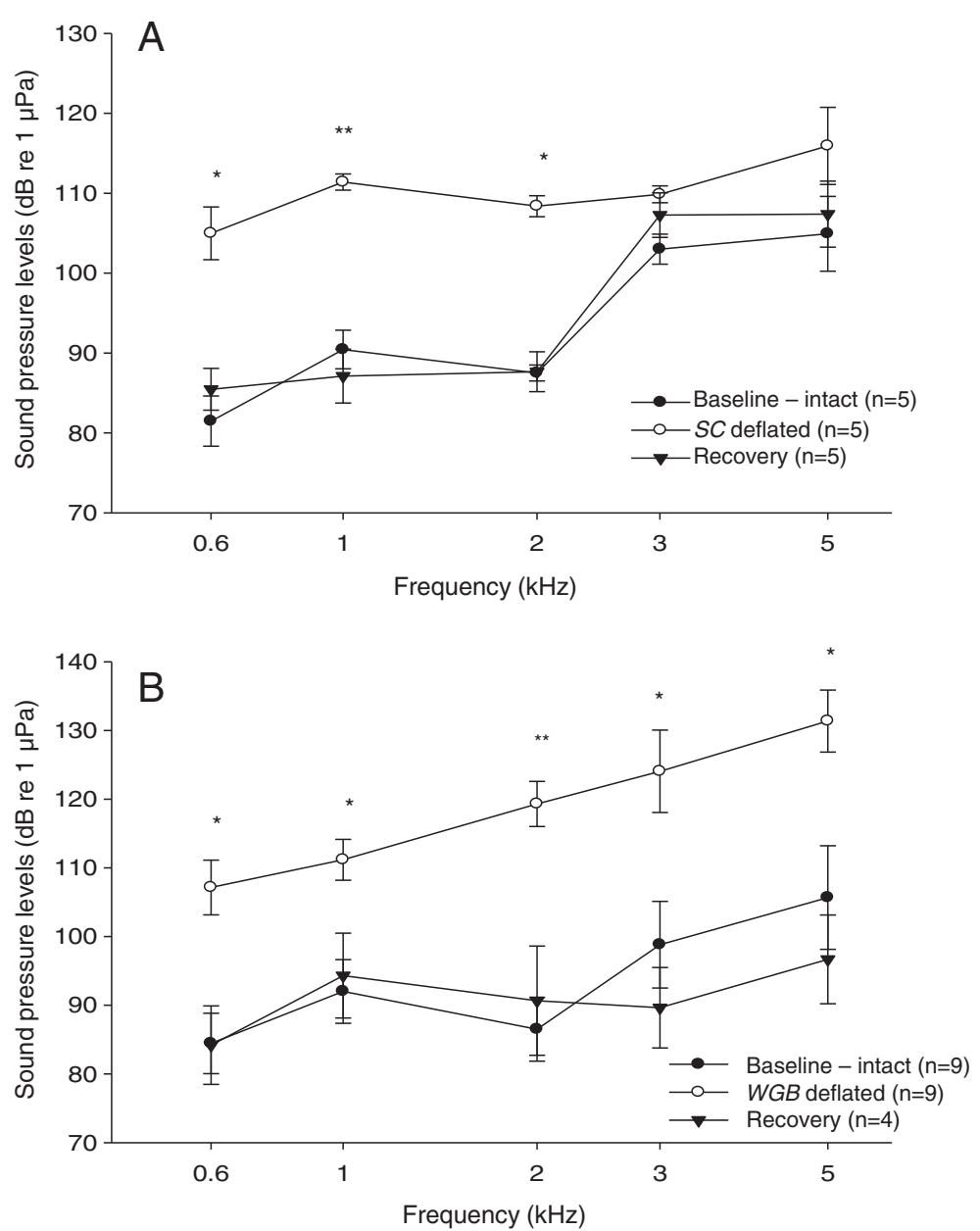

Figure 4 Audiograms of walking catfish at the indicated frequencies. The suprabranchial chamber (SC) (A) or bladder (WGB) was deflated (B) and then allowed to replenish with gas. Audiograms were determined before (baseline) and after (deflated) surgery and after recovery (recovery). Data are shown as means $\pm \mathrm{SE}$. Asterisk $\left(^{*}\right)$ indicates $p<0.05$; double asterisks $\left(^{* *}\right)$ indicate $p<0.01$.

Yasuhikotakia modesta, has lateral trunk channels that stretch from its encapsulated bladder to the outer body wall and are filled with fat and lymph. When Kratochvil and Ladich (2000) manipulated these channels by filling with wettex tissue, it resulted to an increase in auditory thresholds indicating that their encapsulated bladder does have auditory function.

The present findings suggest that the accessory auditory function of the WGB is relative to its volume. At 3.0 and $5.0 \mathrm{kHz}$, a larger bladder may improve hearing ability more than a smaller one (Figure 7; 3.0 and $5.0 \mathrm{kHz}$ ). However, compared to other catfishes which have encapsulated, but smaller, bladder, i.e., Ancistrus ranunculus, Dianema urostriatum, Hemiodontichthys acipenserinus and Hypoptopoma thoracatum (Lechner and Ladich 2008), Corydoras paleatus (Ladich 1999) and C. sodalis (Lechner and Ladich 2008), Otocinclus affinis (Botta 2009), and C. aeneus (Lechner and Ladich 2011), the larger unpaired bladder in walking catfish did not result to lower auditory thresholds at $3.0 / 5.0 \mathrm{kHz}$. In species with free bladder, larger specimens have better hearing ability both at low and high frequency. The hearing thresholds of the African bullhead catfish (Lophiobagrus cyclurus) are lower in larger individuals $(>24.0 \mathrm{~mm})$ than in smaller ones $(<15.3 \mathrm{~mm})$ with an immature ossicular chain. In the African bullhead catfish and squeaker catfish (Synodontis schoutedeni), all specimens with fully developed chain of Weberian ossicles show a size-dependent difference in hearing. Small fish with fully developed chain of ossicles hear better than large fish at higher frequencies and worse than large ones at lower frequencies $(<1.0 \mathrm{kHz})$ (Lechner et al. 2010). The smallest ones, with not yet fully developed chain of ossicles, hear worse than all other groups at all frequencies tested (Lechner et al. 2011). Such relationships between size and hearing ability were not observed in adult goldfish (Popper 1971) or zebrafish (Higgs et al. 2003), both of which possess a well-developed Weberian 

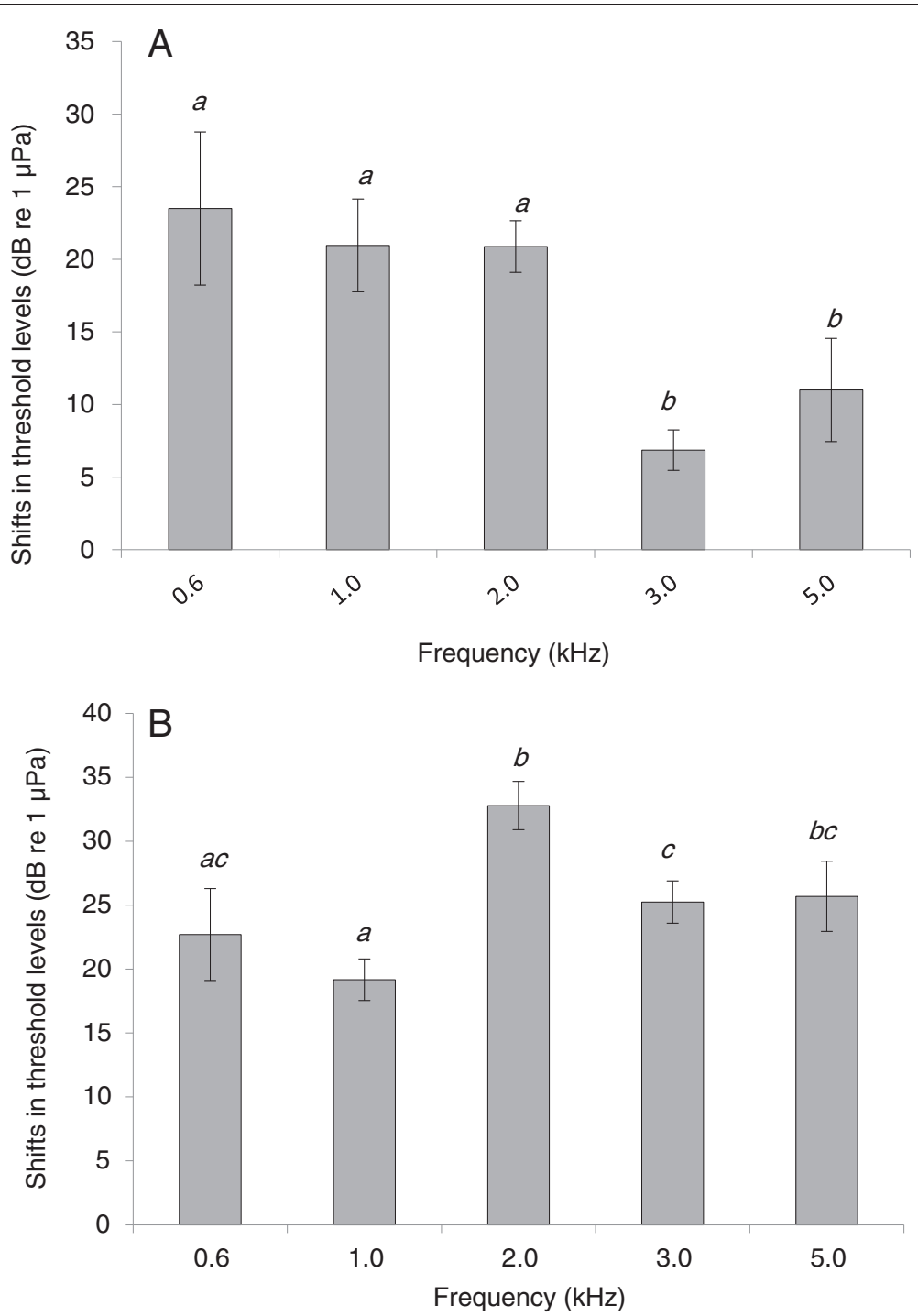

Figure 5 Auditory threshold shifts at the indicated frequencies in catfish after gas removal. (A) Deflation of the suprabranchial chamber. (B) Deflation of the bladder. Data are shown as means \pm SE. Bars with different letters indicate significant difference $(p<0.05)$.

chain. The differences between these species and walking catfish are probably not related to the development of the Weberian chain, as this structure should have been fully developed in the specimens used (Radermaker et al. 1989; see review in Coburn and Grubach 1998). As such, the underlying mechanism remains to be investigated.

The gas bubbles in the SC of gouramis enhance hearing between 0.3 and $4.0 \mathrm{kHz}$ (Yan 1998). Our results showed that the gas in the SC of walking catfish only performed such hearing aid role at lower frequencies, i.e., $<3.0 \mathrm{kHz}$. At frequencies between 0.6 and $2.0 \mathrm{kHz}$, gas removal from the $\mathrm{SC}$ in walking catfish resulted in a mean threshold increase of $21.8 \pm 1.4 \mathrm{~dB}$, a similar increase to that observed in SC-deflated kissing gouramis and dwarf gouramis at the same frequencies. However, threshold increases were not as great as those observed in SC-deflated blue gouramis, which have a distinctly larger SC. The auditory capacity of the gourami SC is suggested to be relative to its gas volume, i.e., species with a larger SC exhibit enhanced hearing (Yan 1998). However, no significant correlation was found between $\mathrm{SC}$ volume and hearing function in walking catfish. It should be noted that the range of SC volumes $(359 \mu \mathrm{l}$, range 290 to $420 \mu \mathrm{l}$ ) in the walking catfish used in experiment 2 was less than that previously reported in blue gouramis, dwarf gouramis, and kissing gouramis by Yan (1998) $(204 \mu \mathrm{l}$, range 126 to $290 \mu \mathrm{l} ; 151 \mu \mathrm{l}$, range 68 to $292 \mu \mathrm{l}$; and $100 \mu \mathrm{l}$, range 72 to $184 \mu \mathrm{l}$, respectively).

\section{The respective auditory roles of the SC and WGB}

Both the encapsulated WGB and SC improve the hearing ability of walking catfish. However, they appear to function 

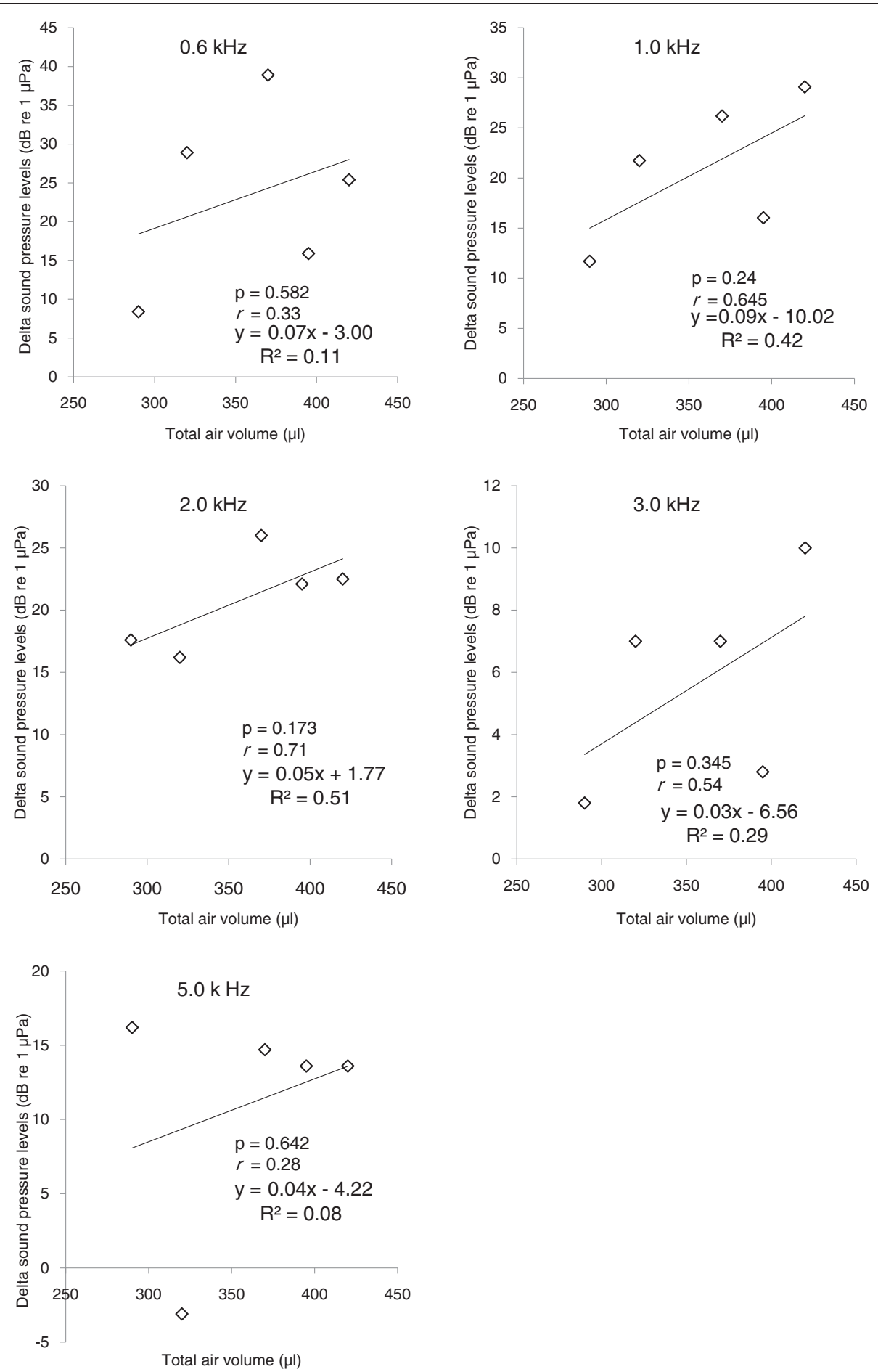

Figure 6 Correlations between auditory threshold shifts and suprabranchial chamber gas volume at the indicated frequencies.

Threshold shifts in each individual after gas removal were plotted against suprabranchial chamber volume. $N=5$ for all frequencies. Regression equation with $\mathrm{R}$ squared $\left(R^{2}\right)$ and Pearson's correlation coefficients $(r)$ with $p$ values are shown.

at a different range of frequencies. In walking catfish, the WGBaids hearing at a broad range of frequencies, while the auditory role of the $S C$ is restricted to lower frequencies. A clear synergistic effect of these two structures on hearing was observed between 0.6 and $2.5 \mathrm{kHz}$, but this was not the case at higher frequencies $(>3.0 \mathrm{kHz})$.

In the present study, the average volume of gas in the WGB was found to be slightly, but not significantly, 

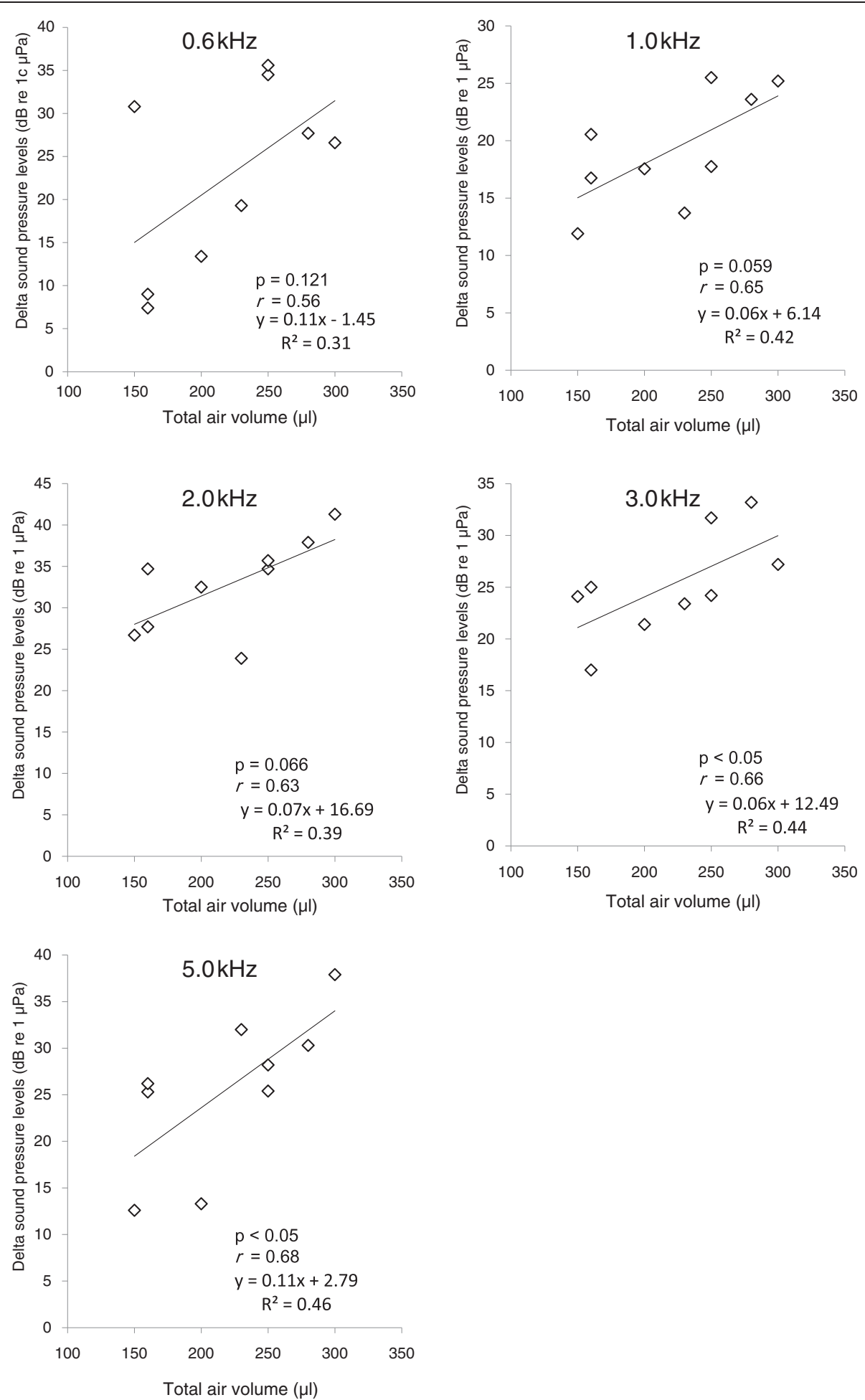

Figure 7 Correlations between auditory thresholds shifts and bladder gas volume at the indicated frequencies. Threshold shifts in each individual after gas removal were plotted against bladder volume. $N=9$ for all frequencies. Regression equation with $\mathrm{R}$ squared $\left(R^{2}\right)$ and Pearson's correlation coefficients $(r)$ with $p$ values are shown. Significant correlations $(p<0.05)$ were observed at 3.0 and $5.0 \mathrm{kHz}$. 


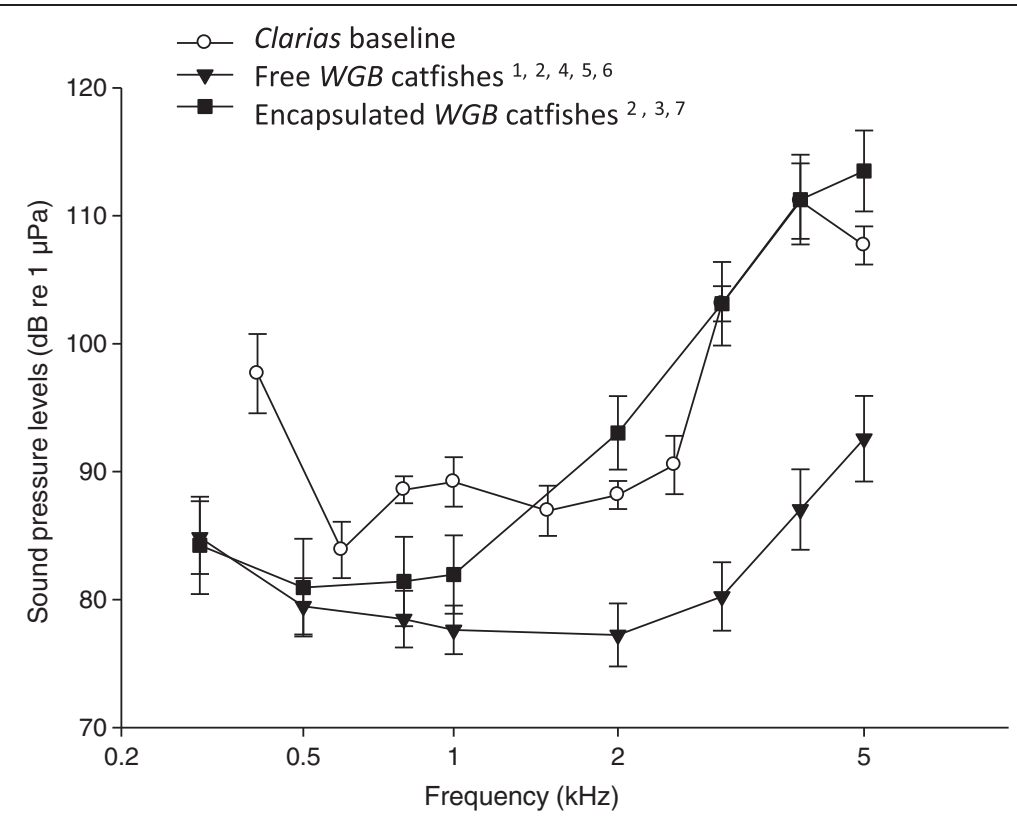

Figure 8 Audiograms of intact walking catfish (Clarias batrachus) (open circles), catfish with encapsulated bladders, and catfish with free bladders. The data for the latter two groups were re-plotted by the means thresholds of each investigated species published previously. Eight species of catfish with encapsulated bladders in solid squares: superscripted two, Corydoras paleatus from the study of Ladich 1999; superscripted three, Ancistrus ranunculus, Corydoras sodalis, Dianema urostriatum, Hemiodontichthys acipenserinus, Hypoptopoma thoracatumfrom the study of Lechner and Ladich 2008; superscripted four, Otocinclus affinisfrom the study of Botta 2009; superscripted eight, Corydoras aeneus from the study of Lechner and Ladich 2011. Sixteen species with free bladders in reversed triangles: superscripted one, Arius felisfrom the study of Tavolga 1982; superscripted two, Platydoras armatulusfrom the study of Ladich 1999; superscripted three, Ariopsis seemanni, Batrochoglanis raninus, Malapterurus beninensis, Synodontis schoutedeni, Trachelyopterichthys taeniatusfrom the study of Lechner and Ladich 2008; superscripted five, Ictalurus punctatus from the study of Wyoscki et al. 2009; superscripted six, Synodontis schoutedeni from the study of Lechner et al. 2010; superscripted seven, Lophiobagrus cyclurusfrom the study of Lechner et al. 2011; superscripted eight, Silurus glanis from the study of Lechner and Ladich 2011; superscripted nine, Acanthodoras spinosissimus, Agamyxis pectinifrons, Amblydoras affinis, Hemidoras morrisi, Megalodoras uranoscopus, Oxydoras nigerfrom the study of Zebedin and Ladich 2013. Data at the frequencies below $300 \mathrm{kHz}$ are not shown.

smaller than that in the SC. Unlike the SC, the bladder in walking catfish does not connect directly to the inner ear but is linked by a Weberian chain. The importance of the Weberian chain linkage in otophysines has been demonstrated in goldfish, in which extirpation of the tripus results in a frequency-dependent decrease in hearing sensitivity (from $7 \mathrm{~dB}$ at $100 \mathrm{~Hz}$ to $33 \mathrm{~dB}$ at $2 \mathrm{kHz}$ ) and a loss in the ability to detect $4 \mathrm{kHz}$ tone bursts (Ladich and Wysocki 2003). Our findings suggest that the ossicular linkage between the bladder and the inner ear may be beneficial to high frequency sound transmission, and thus, the SC functions more effectively at higher frequencies.

\section{Conclusions}

To summarize, the SC and encapsulated WGB have synergistic roles in the enhancement of hearing in walking catfish. Although the SC functions effectively at lower frequencies, it is unable to replace the role of the WGB at higher frequencies. Therefore, although the remaining bladders that create buoyancy may be disadvantageous for a benthic species, their role in hearing enhancement may have ensured their retention during evolution.

\section{Competing interests}

The authors declare that they have no competing interests.

\section{Authors' contributions}

YTS carried out the experiments and drafted the manuscript. ISC made comments on the manuscript. HYY designed the ABR method and revised the manuscript. All authors read and approved the final manuscript.

\section{Acknowledgements}

This study was supported by intramural research grants from Academia Sinica to HY Yan. During the preparation of this manuscript, HY Yan was supported by a fellowship from the Hanse-Wissenschaftskolleg Institute for Advanced Study, Delmenhorst, Germany. The English text was edited by Professor Duncan Wright.

\section{Author details}

${ }^{1}$ Marine Research Station, Institute of Cellular and Organismic Biology, Academia Sinica, 23-10, Dawen Road, Jiaoshi 26242, Taiwan. ${ }^{2}$ Institute of Marine Biology, National Taiwan Ocean University, Keelung 20224, Taiwan. ${ }^{3}$ Hanse-Wissenschaftskolleg Institute for Advanced Study, Lehmkuhlenbusch 4, Delmenhorst 27753, Germany. 
Received: 1 October 2013 Accepted: 20 December 2013

\section{Published: 2 January 2014}

\section{References}

Akamatsu T, Nanami A, Yan HY (2003) Spotlined sardine Sardinops melanostictus listens to 1-kHz sound by using its gas bladder. Fisheries Sci 69:348-354

Alexander RMN (1964) The structure of the Weberian apparatus in the Siluri. Proc Zool Soc Lond 142:419-440

Alexander RMN (1966) Physical aspects of swimbladder function. Biol Rev 41:141-176

Botta SKKR (2009) The development and role of peripheral auditory structures in Otocinclus affinis. Masters Theses \& Specialist Projects. Western Kentucky University, Paper 128

Bridge TW, Haddon AC (1893) Contributions to the anatomy of fishes II. The air-bladder and Weberian ossicles in the siluroid fishes. Philos Trans R Soc London Ser B 184:65-333

Chardon M, Parmentier E, Vandewalle P (2003) Morphology, development and evolution of the Weberian apparatus in catfish. In: Arratia G, Kapoor BG, Diogo R (ed) Catfishes, vol 1. Science Publishers, USA, pp 71-120

Coburn MM, Grubach PG (1998) Ontogeny of the Weberian apparatus in the armored catfish Corydoras paleatus (Siluriformes: Callichthyidae). Copeia 1998:301-311

Fay RR, Popper AN (1974) Acoustic stimulation of the ear of the goldfish (Carassius auratus). J Exp Biol 61:243-260

Fay RR, Popper AN (1975) Modes of stimulation of the teleost ear. J Exp Biol 62:379-387

Harris GG, van Bergeijk WA (1962) Evidence that the lateral-line organ responds to near-field displacements of sound sources in water. J Acoust Soc Am 34:1831-1841

Hawkins AD, Myrberg AA (1983) Hearing and sound communication under water. In: Lewis B (ed) Bioacoustics: acomparative approach. Academic, New York, pp 347-405

Higgs DM, Rollo AK, Souza MJ, Popper AN (2003) Development of form and function in peripheral auditory structures of the zebrafish (Danio rerio). J Acoust Soc Am 113:1145-1154

Kenyon TN, Ladich F, Yan HY (1998) A comparative study of hearing ability in fishes: the auditory brainstem response approach. J Comp Physiol A 182:307-318

Kleerekoper H, Roggenkamp PA (1959) An experimental study on the effect of the swimbladder on hearing sensitivity in Ameiurus nebulosus (Lesueur). Can J Zool 37:1-8

Kratochvil H, Ladich F (2000) Auditory role of lateral trunk channels in cobitid fish. J Comp Physiol A 186:279-285

Kroese ABA, Schellart NAM (1992) Velocity- and acceleration-sensitive unit in the trunk lateral line of the trout. J Neurophysiol 68:2212-2221

Ladich F (1999) Did auditory sensitivity and vocalization evolve independently in otophysan fishes? Brain Behav Evol 53:288-304

Ladich F, Popper AN (2004) Parallel evolution of fish hearing organs. In: Manley GA, Popper AN, Fay RR (ed) Evolution of the vertebrate auditory system. Springer, New York, pp 95-127

Ladich F, Wysocki LE (2003) How does tripus extirpation affect auditory sensitivity in goldfish? Hear Res 182:119-129

Laming PR, Morrow G (1981) Contribution of the swimbladder to audition in the roach, (Rutilus rutilus). Comp Biochem Physiol A 69:537-541

Lechner W, Ladich F (2008) Size matters: diversity in swimbladders and Weberian ossicles affects hearing in catfishes. J Exp Biol 211:1681-1689

Lechner W, Ladich F (2011) How do albino fish hear? J Zool 283:186-192

Lechner W, Wysocki LE, Ladich F (2010) Ontogenetic development of auditory sensitivity and sound production in the squeaker catfish Synodontis schoutedeni. BMC Biol 8:10. doi:10.1186/1741-7007-8-10

Lechner W, Heiss E, Schwaha T, Glosmann M, Ladich F (2011) Ontogenetic development of Weberian ossicles and hearing abilities in the African bullhead catfish. PLoS One 6:e18511

Münz H (1989) Functional organization of the lateral line periphery. In: Coombs S, Görner P, Münz H (ed) The mechanosensory lateral line. Springer, New York, pp 285-298

Nelson JS (2006) Fish of the world, 4th edition. Wiley, New York

Popper AN (1971) The effects of size on the auditory capacities of the goldfish. J Aud Res 2:239-247

Radermaker F, Surlemont C, Sanna P, Chardon M, Vandewalle P (1989) Ontogeny of the Weberian apparatus of Clarias gariepinus (Pisces, Siluriformes). Can J Zool 67:2090-2097
Tavolga WN (1982) Auditory acuity in the sea catfish (Arius felis). J Exp Biol 96:367-376

Wolf K (1963) Physiological salines for fresh-water teleosts. Prog Fish-Cult 25:135-140

Wysocki LE, Montey K, Popper AN (2009) The influence of ambient temperature and thermal acclimation on hearing inan eurythermal and a stenothermal otopyhsan fish. J Exp Biol 212:3091-3099

Yan HY (1998) Auditory role of the suprabranchial chamber in gourami fish. J Comp Physiol A 183:325-333

Yan HY (2004) The role of gas-holding structures in fish hearing: an acoustically evoked potentials approach. In: von der Emede G, Mogdans J, Kapoor BG (ed) The senses of fish: adaptations for the reception of natural stimuli. Narosa Publishing House, New Delhi, pp 189-200

Yan HY, Curtsinger WS (2000) The otic gasbladder as an ancillary auditory structure in a mormyrid fish. J Comp Physiol A 186:595-602

Yan HY, Fine ML, Horn NS, Colon WE (2000) Variability in the role of the gasbladder in fish audition. J Comp Physiol A 186:435-445

Zebedin A, Ladich F (2013) Does the hearing sensitivity in thorny catfishes depend on swim bladder morphology? PLoS One 8:e67049

doi:10.1186/1810-522X-53-1

Cite this article as: Shao et al:: The auditory roles of the gas bladder and suprabranchial chamber in walking catfish (Clarias batrachus). Zoological Studies 2014 53:1.

\section{Submit your manuscript to a SpringerOpen ${ }^{\odot}$ journal and benefit from:}

- Convenient online submission

Rigorous peer review

- Immediate publication on acceptance

- Open access: articles freely available online

- High visibility within the field

- Retaining the copyright to your article

Submit your next manuscript at $>$ springeropen.com 